ISSN: 2638-5279

Volume 1, Issue 2, 2018, PP: 21-29

\title{
Social Policy and Narrative: The Global and State Contradictions of Care Jason L. Powell
}

University of Chester, UK. j.powell@chester.ac.uk

*Corresponding Author: Prof. Jason Powell, PhD, FHEA, FRSPH, FRSA, Department of Social and Political Science, Westminster Building, The University of Chester, Parkgate Road, Chester, CH1 4BJ, UK.

\section{Abstract}

This article provides a critical assessment of the assumptions and narratives underpinning the development of social policy initiatives targeting caring relationships based upon family ties. At the time of writing in late 2018, the impact of globalization has had a profound impact but we cannot underemphasise state power in examining care policy, theory and practice. Hence, deploying a narrative approach attention is drawn to the ways in which family identities are open to a far greater range of negotiation than is assumed by policy. Drawing on the United Kingdom as a case example, questions are posed about intergenerational relations and the nature of late life citizenship. The comparatively recent invention of narratives supporting 'informal care' and the link with neo-liberal and 'third way' notions of active citizenship are explored. As is the failure of policy developments to take into account the diversity of care giving styles and the complexity of caring relationships. It is argued that the uneven and locally specific ways in which policy develops enables the co-existence of a complex range of narratives about family, caring and ageing which address diverse aspects of the family life of older people in often contradictory ways.

\section{INTRODUCTION}

There has been a growing interest in informal care and old age within the European social policy and helping professions literature of recent years from Tony Blair to Gordon Brown to David Cameron to Theresa May (1, 2). The political reasons for such growth are as much social, economic as they are for academic reasons. The British government, in particular, has long recognized that informal care is important for social and economic needs and this should be replicated through an academic understanding of social policy associated with supporting families. However, the effects of globalization and the potential of intergenerational relations as a focus for the analysis of social change has been largely neglected also (3).

The proliferation of adjuvant ideologies evolving out of burgeoning free-market economies along with an accompanying diffusion of instrumental rationality, standardization, commoditization or secularism have become embedded in our thinking, challenging all other relational metrics of daily life that impacts on how we view care and who manages it. In the process, modes of interaction and standards of assessing relational status or personal worth are recast. In both developed and emerging economies the nature of work and the meaning of careers are also undergoing major reformulations. There is a global softening of labor markets linked to downsizing of local employment opportunities, redundancies, a spate of subcontracting arrangements, and an economic volatility abetted by technological innovations that chip away at employment security, wage or benefit packages bringing a degree of economic and existential uncertainty to greater numbers of people. Of course, such changes are not distributed evenly across all forms of employment, further exacerbating inequalities.

It should also be stressed that adversity does not appear to strike women and men equally - and it is certainly reasonable to say that disadvantage begets gendered disadvantage when downturns occur (29, 30). Women are disproportionately among the most disadvantaged and with age even greater hardships 
accrue to them. Adding to the intricacies of these unparalleled changes is the velocity with which they are taking place and the fact that they are accompanied by a deepening division between those whose principal pursuits are in subsistence or service sector markets and their counterparts who are primarily involved in large-scale export, international sectors, or equity markets. Together these forces are bringing about a profound imbalance within and between populations as one group shares in the generation of wealth while the other becomes increasingly dependent and is being subordinated to decisions made in the other sector, by a cartel half a world away (29).

This is not to say that states are mere minions of transnational interests but it is no longer the case that nation-state sovereignty can be taken-for-granted in the care policy realm. Nor is it necessarily the case that state policies are as all-powerful as they once were in shaping daily life (29). The welfare state of the last century has been replaced by a competitive state of the 21st century, always mindful of its global positioning (30). Some propose that a parallel concept may provide insights into the vagaries of post-industrial publicsector decision making. To make sense of domestic versus international priorities and their effect on daily life, scholars would do well to come to terms with the notion of "non-sovereign power" as it applies to social justice, autonomy, monetary policies and capital mobility, and other forms of extra-national pressures emending local care policies. It could be asserted that to date there has been a real lag between transnational developments and the way analysts think of social policies especially as applied to care. Some attribute the stumbling blocks in conceptualization to the disjunctures between various vectors characterizing this world-in-motion that produce fundamental problems of livelihood, equity, suffering, justice, and governance (29). In this characterization, proximate social issues have causes that are hardly local and call for non-parochial perspectives if they are to be addressed.

One of the most significant impacts of globalization is that it has brought an intensification of worldwide social relations which link distant localities in such a way that local happenings are shaped by events occurring many miles away and vice versa (8). As a consequence, few governments are eager to make decisions separately from their reliance on global enterprise; it is as though they are in a situation of shared sovereignty, having to negotiate between domestic, international, corporatist and transnational interests (29). NGOs such as the World Bank and the International Monetary Fund have also become architectural partners in local policy deliberations by sanctioning preferred welfare policies as a condition of their support of monetization (30). Even so, nation-states nonetheless serve important administrative functions in a world dominated by transnational corporate interests and it is unlikely that governmental responsibilities are either going to be usurped or allowed to wither in light of their functionality (29). It is not too far fetched to say that certain transnational interests see themselves as having universal jurisdiction, assertions of state autonomy notwithstanding.

With the spreading of these transformations has come a reshuffling of local priorities, with governmental emoluments directed or redirected to areas defined as having the greatest public importance and bringing the greatest returns. Of course the realities behind that assertion are deserving of close scrutiny as the policy process is unquestionably political and the state must mediate rival claims as it serves as the principal mechanism by which revenues are collected and resources distributed. Meanwhile, social entitlements, expenditures and daily experience for people who may not fully grasp the raison d'être behind their situations reflect these same priorities. It has been suggested that social policy regimes are regularly structured to be consistent with other forms of social stratification within a nation state such as the UK (29). To the extent there is a convergence in social welfare policies around the globe it might not be mere coincidence that social stratification and social class divisions are growing more pronounced in the face of globalization that lie at the heart of care relations. In light of global economic flows, the salience and permeability of national borders, whether in Europe, the western hemisphere, or in the East are a different matter than they were even half a century ago (29). In terms of domestic care policies, the impact of international economic relations has recontoured the landscape, so to speak, all the way to the regionalization and appropriation of economic relations. What were once bold lines of demarcation are now dotted lines more suggestive of administrative spheres than jingoistic borders. In the global century, deregulated markets are tightly integrated with political and social transformations, 
affecting local circumstances and communality (4, 29). All in all, the globalizing influences of the early 21st century are producing a distinctive era in social history linked to the emergence of transnational actors as well as economics and technologies that are helping fuel the shifts. Global economic change portends more than alterations in per capita income, the nature of financial products and currency markets, or the rapid circulation of goods, communication or technologies. It is precursor to broad cultural and political shifts that challenge pre-contact arrangements, notions of social justice and solidarity, as well as local interaction patterns. In a post-modern world, globalization is creating interlocking dependencies linked to the ways in which priorities are ordained by interests that impact on care and the family. Global pressures play a key role on nation states. However, nation states themselves have enormous ideological power to shape the interests of care; what it means; who it impacts on and how does it leave the family?

This paper faces up to this challenge and takes the UK as a case example which can shed light on wider global trends associated with caring, family and ageing. Conceptually, 'family' is 'taken for granted' as a term and is not with a fixed meaning (4). Policy makers and politicians, for example often use the idea of the family in their attempts to shape social relationships such as informal caring. In common-sense everyday language, people indicate what they mean by family when they are interacting with each other. As we become aware of the increasing fluidity of age-based roles and relationships and the multiple influences that impinge on family behaviour, it has also become attractive to view families and family members as 'living' by certain scripts. To understand families and informal care, we must recognize that the meaning of the family changes in response to a wide variety of social, economic, political, cultural and inter-personal conditions. Policy is both an attempt to shape and is itself shaped by these meanings. Modern social systems depend upon families. One reason is that children come to be citizens because of the instruction and training provided in the private life of families (5). Indeed, it is in families that people are expected to learn what it is to become a responsible citizen. Western governments generally assume an organization of society that requires families to perform work of caring for its members. In the UK, for example much politicking has surrounded family life, including controversies over informal care coupled with single parenting, financial support by absent fathers and proposed legal reforms concerning divorce, domestic violence and family homes (1). Policy discourses have centred on marking changes in the ways women, men, children and 'wider family' members inter-relate, have relationships with one another and the consequences of such changes for individuals and for society as a whole. The popularization of 'narrativity' has increased in the social sciences, both as a method of undertaking research (6) and as a technique for modifying the self $(7,8)$. Davidson (9) suggests that older people construct their own analytical models of personal identity based on lived experience and on narratives already existing in their everyday environments. By using a narrative approach, the meaning of family can be told through stories about the self as well as ones 'at large' in public discourse (30). Self-storying, draws attention to the ways in which family identities are both more open to negotiation and are more likely to be owned and worked on by individuals themselves. Families are made up of interpersonal relationships within and between generations that are subject to both the formal rhetoric of public discourse, and the selfstories that connect them together. The notion of family is, then, an amalgam of policy discourse and everyday negotiation and as such alerts us to the wider social implications of those relationships for the social construction of informal care. The rhetoric of social policy and the formal representations of adult ageing and family life that one finds there, provide a source of material for the construction of identity and a series of spaces in which such identities can be performed and surveillance maintained (9). It is perhaps not overstating the case to say that the 'success' of a family policy can be judged from the degree to which people live within the stories of family created by it. Indeed, the relationship between families and social policy has been consecutively rewritten in the social policy literature. Each time a different story has been told and alternative aspects of the relationship have been thrown into high relief. It might even be argued that the family has become a key site upon which expected norms of late life citizenship are being built. The structure of the article is in four parts. First, we start by mapping out the emergence and consolidation of neoliberal family policy and its relationship to and emphasis on family obligation, state surveillance and active citizenship. Secondly, we highlight both the ideological continuities and discontinuities of 
the social democratic 'turn' and their effects on older people and the family. Thirdly, research studies are drawn on to highlight how 'family' has been recognized by governments in recent years, as a particular way of 'storying' the relationship between carers and cared for. Finally, we explore ramifications for researching family policy and old age by pointing out that narratives of inclusion and exclusion often coexist. A neoliberal story of family and informal care Political debate since the Thatcher years, has been dominated by neoliberalism, which argues the existence of autonomous, assertive, rational individuals who must be protected and liberated from 'big government' (1, 3). Indeed, Walker and Naegele (10) claim a startling continuity across Europe is the way 'the family' has been positioned by governments as these ideas have spread beyond their original 'English-speaking' base. Neoliberal policies on the family, have almost always started from a position of laissez-faire, excepting when extreme behaviour threatens its members or wider social relations. Using the UK as a case example, it can be seen that that neoliberal policy came to focus on two main issues. Whilst both only represent the point at which a minimalist approach from the state touches family life, they come to mark the dominant narrative through which ageing and family are made visible in the public domain. On the one hand, increasing attention was paid to the role families took in the care of older people who were either mentally or physically infirm. A series of policy initiatives (11, 12) recognized that families were a principal source of care and support. 'Informal' family care became a key building block of policy towards an ageing population. It both increased the salience of traditional family values, independence from government and enabled a reduction in direct support from the state. Wider economic priorities, to 'roll back the state' and thereby release resources for individualism had become translated into a family discourse about caring obligations and the need to enforce them. If families ceased to care, then the state would have to pick up the bill. It was not that families were spoken of as being naturally abusive. Neither was the 'discovery' of familial abuse linked to community care policy outside academic debate (13). Discourses on the rise of abuse and on informal care remained separate in the formal policy domain. However, a subtle change of narrative tone had taken place. Families, rather than being seen as 'havens against a harsh world', were now easily perceived as potential sites of mistreatment, and the previously idealized role of the unpaid carer became that of a potential recalcitrant, attempting to avoid their family obligations (14). Although it appeared that familial caring was actually moving away from relationships based on obligation and towards those based on negotiation (15). Family commitment has been shown by Bengtson and Achenbaum (16) to vary depending upon the characteristic caregiving patterns within particular families. Individualistic families provided less instrumental help and made use of welfare services, whereas a second, collectivist pattern offered greater personal support. Bengtson et al. (17) observed that 'tightknit' and 'detached' family styles were often common across generations. Unfortunately, policy developments have rarely taken differences in caregiving styles into account, preferring a narrative of idealized role relationships.

\section{A 'New Labour' Trend? Social Democracy, FAMILY AND CARING}

Social democratic policies towards the family arose from the premise that by the early 1990s, the freemarket policies of the Thatcher years had seriously damaged the social fabric of the nation state. A turn to 'the third way', emerging under Clinton, Blair and Schroeder administrations in the US and parts of Europe, attempted to find means of mending that social fabric, and as part of it, relations between older people and their families. The direction that the new policy narrative took is summarized in UK Prime Minister Blair's (1996) statement that 'The most meaningful stake anyone can have in society is the ability to earn a living and support a family' (3). Work, or failing that, care-like activities, slowly began to emerge, delineating new narratives. According to Giddens (18), a new partnership is needed between government and civil society. Government support to the renewal of community through local initiative, gives an increasing role to 'voluntary' organizations, and significantly, supports the 'democratic' family characterized by mutual respect, autonomy, decisionmaking through communication and freedom of violence. It is argued that social policy should be less concerned with 'equality' and more with 'inclusion', with community participation reducing moral and financial dependence. Through an increased awareness of the notion of ageism, the influence of European ideas about social inclusion and North American social communitarianism, families and older people found themselves transformed into 'active citizens' who 
should be encouraged to participate in society, rather than as a burden upon it $(19,20)$. A UK policy document, entitled Building a Better Britain for Older People, is typical of a new genre of western policy, restorying the role of older people: 'The contribution of older people is vital, both to families, and to voluntary organizations and charities. We believe their roles as mentors - providing ongoing support and advice to families, young people and other older people - should be recognized. Older people already show a considerable commitment to volunteering. The Government is working with voluntary groups and those representing older people to see how we can increase the quality and quantity of opportunities for older people who want to volunteer' (21). Older people are portrayed as holding a key role in the stability of both the public sphere, through caring, work and volunteering, and in the private sphere, primarily through support and advice to younger people. Paradoxically, the family also provides a site for voluntary activity and active citizenship through the support of informal caring relationships (22). The social relations of informal care There are nearly six million people providing informal care in the UK (22) of which, over half, care for someone over the age of 75 years. However, only $18 \%$ of people involved in caring report the effects of age as the main reason for the person requiring care. At the same time there is little UK research directly related to calculating the risk of requiring care in older age and what there is has been based on USA insurance models (23). The notion of informal care has a recent and complex history in social policy. Generally taken to name the activity of caring for another person in a private dwelling outside of a formal arrangement for payment and underpinned by obligations structured by marital or family ties, this apparent simplicity fails to represent the complexity and diversity of caring relationships. The idea that informal care has a recent history should not obscure the fact that caring relationships have existed between people across millennium, nor that obligation to weaker or impaired members of families and communities has not been addressed through a range of formal and informal activities. However, alongside the narratives of family life, it is important to dispense with Romanic notions of a 'Golden Age' of family and community care. In the UK, we only need to look to the legacy of the Poor Law and its discursive product of the deserving and undeserving poor (29). The material presence of this legacy in large scale institutions (hospitals) for older people remained a key characteristic of social intervention well into the last quarter of the 20th century $(1,23)$. If we take up a position in the 1970s, carers are largely invisible in social policy discourse while informal care as a category of intervention and need has yet to be invented. As noted earlier, this change emerged with the neoliberal restructuring of welfare regimes across the western world in which a discourse of the primacy of the family and family obligation is promoted and reinforced through social policy. Enshrined in statements such as the subsidiarity principle in the EU the idea that the family is the first and most important source of social welfare and support became articulated in the policy narratives of family life (24). As noted earlier, a series of policy initiatives in the UK recognized the role of families as the principle source of support Carers emerge as a target of social policy in the late 1980s and along with this informal care is invented as both the aim and product of social intervention. In line with neoliberal discourse the narratives of family life provide two options for families looking to support a frail or impaired member both of which involve forms of privatization: a privatization via the family or a privatization via the market. Through a perverse set of conditions the market option expanded rapidly in the UK in the 1990s largely fuelled by older people being moved out of the large state institutions rather than older people or their families choosing this option. Paradoxically, concerns over informal care focused on the obligations of families and the disproportionate way this impacted on women, and the contradictions between a narrative of obligation and the emergence of new categories of abuse and neglect. However, within a decade the neoliberal hegemony had given way to a new socialdemocratic position which while retaining much of the narrative around the primacy of the family also accepted a level of diversity in family-like arrangements not tolerated within the previous narrative. At the same time, the background of economic slowdown that provided the context for much of the earlier targeting of the family had given way to a more dynamic economic situation with larger numbers of women being drawn into the labour market (22). The policy narrative took up a version of a social citizenship based on work and community activity, and as part of this narrative a new partnership between carers and the state was described. The obligation to care for a relative or family member became partly disentangled 
from the discourse of family responsibility where the duty to care came as an implicit part of the marriage contract. The narrative of the family is then rearticulated with a quality of life discourse that proposed a number of expectations carers could hold of the state. Central to this was the expectation that carers can remain in work if they wish where they will receive protection of employment and pension rights. Moreover, the communitarian elements of the government narrative promoted not only the civil good of informal care but also promoted the civic responsibility to support carers with a new corps of volunteers (30). Despite this package and the support of a communitarian discourse there remain tensions and contradictions around the obligation to care and levels of compensation. Government: while acknowledging the potential financial costs of caring should the willingness or ability of people to engage in informal care decline; is nevertheless concerned not to provide levels of compensation, in particular financial compensation, which might undermine the moral commitment felt by carers. This could have perverse consequences for caring (23). At the same time, the obligation to care is reinforced by the explicit suggestion that the alternative, residential care, could have a detrimental effect on person $(22,24)$. This is accompanied by state powers to sequestrate the financial assets of individuals receiving market-based solutions to care. The analyses of the way discourses are embedded in policy has been criticized for neglecting the personal level where an even more complex set of narratives are at play. Recently, policy has focused on integrated health and social care (29). Such Engagement in care brings together in an unstable relationship two discourses: one relates to doing health care i.e. the range of activities a person might engage in while supporting another person, while the other relates to being caring: a more complex proposition that involves emotional labour and a felt responsibility for another individual[s] (29). Alongside the complex interplay of this narrative of doing care and being caring comes recognition that the boundaries between formal and informal care are unstable. Paid carers often report a sense of obligation to people they are supporting beyond what they are employed to do. Studies of paid care in both the USA and the UK have illustrated the permeability of the boundaries between labour, intimacy and love (25, 26). Moreover, the hierarchical relationship between the dependent and the independent, as painted in the policy narrative between the cared for, carer and voluntary worker, fails to grasp the reciprocal relationships within caring where emotional bonds and a sense of satisfaction help to cement the dynamics of informal care. This narrative is further destabilized when discourses of gender, sexuality and race are taken into account: where, for example, same sex caring relationships may take place in a different set of 'spaces' other than the home (27); or, in the context of ethnic languages, such as many Asian languages, where there is no narrative through which to discuss the relations described here as informal care (28).

\section{ConCLUSION}

The commodification of care services and relentless obligation to informal care, as it is sometimes called, is abetted by a transfer of issues of citizenship to a forum which is no longer native in its scope but transnational; marked by intergovernmental structures, multinational corporate influence and population changes (29). There is another layer of complexity added by a worldwide tendency to view a number of social issues through a medical lens (30) and the insecurities experienced by the citizenry in general are without parallel in world history. What might be described as apodictic, self-evident truths of tradition tend to lose their currency and help demarcate generational and participatory categories from one another.

In the face of an unswerving drive to be players on the world's stage, enhance market share and survive economic rip-tides, nation-states must balance the demands of competing claimants - leaving them few options but to make hard choices. Not only do they have to adjudicate where to put scarce resources and which groups are deserving of protection or support, but few actions are indemnified against the next economic shortfall meaning they will have to review their priorities anew each time the economic tides turn. It has always been true that in times of plenty promises about solutions to societal woes are an easy pledge to make; during times of scarcity it is a different story and keeping even the best-intentioned promises oftentimes creates real conflicts. Societallevel redefinitions of what is fair and just are a common means to solutions that do not always do well by citizens in need of assistance, undermining personal sense of security and identity as well as social solidarity (29). 
An illustration of a macro-level problem may be helpful for thinking about the type of quandary involved. As nation-states undergo economic development via participation in global commerce, per capita incomes generally increase, never mind for the moment internal disparities, life expectancies increase and demands for healthcare mount (30). Continued change and desires to remain viable in the global economy mean a country will face enduring challenges in providing social safety nets, medical interventions or financing health care protections. To focus on just the health care issue: despite subsidized provisions for indigent citizens, most healthcare coverage around the world is linked to employment and economic productivity (workfare) and as employment is destabilized so too is care (29). Needless to say, employment-based systems are costly, leading to cost shifting which also serves to grant license to employers to cut jobs and move production around to minimize the expense of doing business (5, 8,29 ). For those not covered by employment-based plans, subsidized coverage is oftentimes available but financed by taxes and premiums or by governmentally mandated insurance groups saddled with high expectations and expenditures. But social policies supportive of indigent care for those not involved in economically productive activities are often singled out as a cost sink and are among the first issues put on cost-cutting agenda (30).

In order to comprehend the underpinning of certain forms of inequalities it is also important to examine some of the transformations that are altering people's lives. One post-modernist reality of the 21st century is the existence of a digital divide between those who have always known how to navigate in key-stroke technologies and those "ancients" who learned it later or not at all. Those who are comfortable with the technology have the world at their fingertips and no longer depend on local relationships or role models for solace or validation. The result is an indisputable social segmentation (29). Whatever norms of reciprocity had existed before are likely to falter and fray under the impact of interdicting worldviews in which the deep grammar of sociability is no longer meaningful to those versed in the newer modes of care activity. At the same time, there is an erosion of communities of like minds with shared representations cutting across society at large and fostering social solidarity. Instead they are replaced by segmented, smaller communities and a blurring of ways of knowing the world.
Globalization has thus created an identity crisis, since many are neither local nor global and are overloaded with changing stimulresulting in a 'don't care' attitude, commercial interactions among family members, a rise of individualism and a disequilibrium (30) The problem here is that care is being seen as a domain for the family or private profit by government.

Transnational private enterprises cannot be ignored as they are altering the landscape but they are not doing so single-handedly. It is fair to say there are both private and semi-public but non-governmental organizations (NGOs) involved. Multilateral NGOs are playing an especially crucial role and certainly a role that is influencing developing countries as they sort out their welfare regimes in terms of care and "contracting out". For example, since the issuance of the Berg Report in 1981, the World Bank and the International Monetary Fund (IMF) have become major players on the world's stage oftentimes stipulating structural adjustments and preferred policies nation-states should adopt as a condition of support and in order to attract direct capital investments or other fiscal cooperation, including monetization. One illustration is that the World Bank began urging diminutions in pay-as-yougo (PAYG) pension provisions in favorof means-tested pensions and private provisions in the mid-1990s (29). The World Bank and the IMF have been staunch advocates for over three decades for broadly defined market-led welfare policies as a preferred alternative to un- or under-funded public care services (17). Encapsulating both the criticisms and the confluence of forces fueling such a movement, some assert that the drive for economic integration pays precious little attention to nation-building, national interests or public sector regulatory control in relation to care (30) As a consequence, even nonprofit, social enterprises tend to be doing good badly (29).

Although there is a remarkable absence of consensus, social care is customarily taken to mean statutory governmental intervention designed to provide supportive services and resources to those in need. Right away one question that has to be addressed revolves around eligibility requirements and stipulations of entitlement. Such issues as gender are very much a part of the state, as are discussions of family responsibilities and care policies. At the risk of extreme simplification, whether women's narratives are eligible for social benefits and services in their own rights or as members of a male-breadwinner 
family is an abiding question whenever care regimes are examined. By the same token, gender ideologies are very much an aspect of poverty, labor markets and other market experiences, or the myriad inequalities that cut across the life course and through virtually every facet of experience especially in the UK $(29,30)$.

Social policy development in the UK is subject to local emphasis and elision, which means that it is possible for different, even conflicting narratives of family care and later life to coexist in different parts of the policy system. Each political period generates a discourse that can legitimate the lives of older people and family relations in particular ways, and as their influence accrues, create the potential of entering into varied narrative streams. A key feature of recent social policy history has been that not only have the formal policies been quite different in their tenor and tacit objectives, one from another, they have also addressed different areas of the lives of members of families. Where there is little narrative overlap there is the possibility of both policies existing, however opposed they may be ideologically or in terms of outcome It is possible to see contemporary social policy addressing diverse aspects of the family life of older people in contradictory ways. Contradictory narratives for the family exist in a landscape that is at one and the same time increasingly blurred in terms of roles and relationships and splitoff in terms of narrative coherence. Indeed in a future of complex and multiple policy agendas, it would appear that a narrative of social inclusion through 'active ageing' can coexist with one emphasizing carer obligation and surveillance. Such a co-existence may occasionally become inconvenient at the level of public rhetoric. Diverse yet co-existing policy narratives may become a significant source of risk to identity maintenance within the family. One has to imagine a situation in which family lives are lived, skating on a surface of legitimizing discourse and policy narratives (30).However, nation-states such as the UK still serve important administrative functions in a world dominated by increasingly transnational corporate interests. With few options and having to make hard choices, care provision has seen trends toward commodification of social care while both globalization and state power is affecting social contracts as well. In the face of all these challenges to justice and governance, there must be a twin track approach: social welfare needs to be redefined and extended while market economy must be guided by moral principles that embody fundamental human valuesfor every member of every family requiring care (29).

\section{REFERENCES}

[1] Williams F. Social Policy. 1994, Polity, Cambridge.

[2] Bytheway B, Johnson J. The social construction of 'carers'. In The Social Construction of Community Care (Symonds A, Kelly A eds), 1998, MacMillan, London, 71-90.

[3] Powell J, Biggs S. Managing old age: the disciplinary web of power, surveillance and normalization. Journal of Aging \& Identity 2000; 5: 3-13.

[4] Moen P, Wethington E. The concept of family adaptive strategies. Annual Review of Sociology 1992; 18: 233-51.

[5] Giddens A. Sociology. 1993, Polity Press, Cambridge.

[6] Kenyon G, Ruth J, Mader W. Elements of a narrative gernotology. In Handbook of Theories of Aging (Bengtson V, Schaie K eds), 1999, New York, Springer, 123-51.

[7] McAdams D. The Stories We Live By. 1993, Morrow, New York.

[8] McLeod J. Narrative and Psychotherapy. 1997, Sage, London.

[9] Davidson A. Ethics as ascetics: Foucault, the history of ethics, and ancient thought. In The Cambridge Companion to Foucault (Gutting C ed.), 1994, Cambridge University Press, Cambridge, 115-40.

[10] Walker A, Naegele G. The Politics of Old Age in Europe. 1999, OUP, Buckingham.

[11] Department of Health. Caring for Older People White Paper. 1989, London, HMSO.

[12] Department of Health and Social Security. NHS \& Community Care Act. 1990, HMSO, London.

[13] Biggs S. A family concern: elder abuse in British social policy. Critical Social Policy 1996; 16: 63-88.

[14] Wenger C. Support Networks for Older People. 1994, CSPRD, Bangor.

[15] Finch J, Mason J. Negotiating Family responsibilities. 1993, Routledge, London. 
Social Policy and Narrative: The Global and State Contradictions of Care

[16] Bengtson VL, Achenbaum W. The Changing Contract Across Generations. 1993, Aldine De Gruyter, New York.

[17] Bengtson VL, Giarrusso R, Silverstein M, Wang H. Families and intergenerational relationships in aging societies. Hallym Int J Aging 2000; 2: 3-10.

[18] Giddens A. The Third Way. 1998, Polity Press, Cambridge.

[19] Biggs S. Toward critical narrativity: Stories of aging in contemporary social policy. Journal of Aging Studies 2001; 15: 1-14.

[20] Biggs S, Powell J. A Foucauldian analysis of old age and the power of social welfare. Journal of Aging \& Social Policy 2001; 12: 93-112.

[21] Dept. of Social Security. Building a Better Britain for Older People. 1998, HMSO, London.

[22] Department of Health. Caring about Carers: A National Strategy for Carers. 1999, The Stationery Office, London.

[23] Le Grand J. From knight to knave? Public policy and market incentives. In Risk, Trust and
Welfare (Taylor-Gooby P ed.), 2000, MacMillan, Basingstoke, 21-30.

[24] Poole L. Germany: A conservative regime in crisis. In Comparing Welfare States, 2nd edn (Cochrane A, Clarke J, Gerwirtz S eds), 2001, Sage, London, 153-95.

[25] Fink J. Questions of care. In Care: Personal Lives and Social Policy (Fink J ed.), 2004, The Policy Press, Bristol, 1-42.

[26] Stone D. Caring by the book. In Care Work, Gender, Labour and the Welfare State (Meyer MH ed.), 2000, Routledge, London, 61-87.

[27] Katz S. Busy bodies: activity, aging and the management of everyday life. J Aging Stud 1999; 14: 135-52.

[28] Gunaratnam Y. Call for Care. 1991, Health Education Authority, Kings Fund Centre, London.

[29] Powell, J. Lifecourse and Society. (2018), Nova Science, New York,

[30] Powell, J The Power of Global Aging (2018), Nova Science, New York

Citation: Jason L. Powell. Social Policy and Narrative: The Global and State Contradictions of Care. Open Access Journal of Internal Medicine. 2018; 1(2): 21-29.

Copyright: (C) 2018 Jason L. Powell. This is an open access article distributed under the Creative Commons Attribution License, which permits unrestricted use, distribution, and reproduction in any medium, provided the original work is properly cited. 